stimmung desselben geschah durch Titrirung der abfiltrirten Mutterlauge, wobei also etwa gelöstes Natriumbicarbonat als Ammoniak mittitrirte.

2. Etwa 4,6 Proc. Ammoniak in Form von Chlorammonium in der Mutterlange; die Ermittlung geschah durch Untersuchung der abfiltrirten Mutterlauge im Ammoniakbestimmungsapparat unter Subtraction des den Kreislauf in unverändertem Zustande mitmachendem Ammoniumsulfats.

3. Etwa 0,5 Proc. Ammoniak findet sich in den Ausströmungsgasen der Colonne; dies ergibt sich durch Subtraction der Posten $1+2$ von 6 Proc.

Das unter 1 angeführte Ammoniak bleibt in der Lauge und geht mit derselben in die Destillation; der am feuchten Bicarbonat anhaftende Theil ist so gering, dass er unberücksichtigt bleiben kann.

Das unter 2 angeführte, in der Mutterlauge als Chlorammonium enthaltene Ammoniak (etwa 4,6 Proc.) geht zum grössten Theil in die Destillation, ein kleiner Theil haftet an dem feuchten Bicarbonat und bewirkt neben unzersetztem Chlornatrium, dass die calcinirte Soda statt volle $100^{\circ}$ nur 97 bis $99^{\circ}$ zeigt (entsprechend 0,046 bis 0,138 Proc. Ammoniak), hierfür wird 0,08 Proc. Ammoniak gesetzt, dasselbe findet sich in den aus dem Calcinirapparat abgesaugten Gasen vor; es wird von Wasser absorbirt, welches zur Soolenbereitung dient.

Das unter 3 angeführte Ammoniak wird von den Ausströmungsgasen der Colonne in einen Waschapparat transportirt, wo etwa 0,3 Proc. Ammoniak von Soole aufgenommen wurden, welche unmittelbar darauf behufs Bildung von Fällflüssigkeit in den Ammoniakabsorber gelangt; die unabsorbirten 0,2 Proc. Ammoniak gehen mit den Ausströmungsgasen in einen zweiten Waschapparat, wo etwa 0,17 Proc. von Wasser aufgenommen wird, welches zur Soolenbereitung dient, und welches gemeinschaftlich mit dem unter 2 angeführten Ammoniak des Calcinirapparates die Reinigung der Soole von Gips bewirkt, bez. in der frischen Soole in Form von Carbonat gelöst bleibt. Der Rest ron etwa 0,03 Proc. wird in einem Säurebehälter zurückgehalten.

[Fortsetzung folgt.]

Über den Cholesteringehalt der Thrane. Von

\section{Dr. W. Fahrion.}

Während der Leberthran nach Allen und Thomson (vgl. Benedikt, Analyse der Fette S. 369) 0,46 bis 1,32, nach Salkowski (Z. anal. 26, 565) sogar nur 0,3 Proc. Cholesterin enthält, fand Jean (Monit. sc. 1885, 892) in demselben 6 Proc. einer öligen, nicht verseifbaren Substanz, die sich mit einem Tropfen Schwefelsäure prachtvoll roth färbt. $\mathrm{Da}$ dies den An- schein erwecken könnte, als hätte Jean einen mit Mineralöl gefälschten Thran in Händen gehabt, so habe ich eine Reihe von absolut reinen Leber- und anderen Thranen auf ihren Gehalt an unverseifbaren Substanzen geprüft und zwar nach der von Hoenig und Spitz (d. Z. 1891, 567) angegebenen Methode mit der unwesentlichen Abänderung, dass die 20 cc Petrolätherlösung statt in einem gewogenen Kölbchen direct in der Platinschale auf dem Wasserbad verdampft wurden. Letzteres darf anfangs nicht zu stark kochen, weil sonst durch Spritzen Verluste entstehen können. Dagegen lässt sich, wenn nur die unter $75^{\circ}$ übergehenden Antheile des käuflichen Petroläthers angewendet werden, der letztere auf dem Wasserbad vollständig entfernen und ist ein nachheriges Trocknen im Schrank überflüssig. Die Methode gibt bei sehr rascher Ausführung gut übereinstimmende Resultate und ist daher für die Zwecke der Praxis sebr zu empfehlen, besonders, wenn es sich nur um geringere Mengen unverseifbarer Substanzen handelt. Da die Thrane im Allgemeinen sehr schwer verseifbar sind, so ist sorgfältig darauf zu achten, dass die Verseifung auch eine vollständige ist, weil sonst die Resultate naturgemäss zu hoch ausfallen.

Das Unverseifbare wurde durchweg in Form eines gelben, fettigen, ziemlich fest an der Platinschale haftenden Überzugs erhalten, der sich in Alkohol glatt auföst. Beim Stehen scheidet die alkoholische Lösung, wenn die Menge des Unverseifbaren nicht zu gering ist, Krystalle ab. Die von Jean angeführte Rothfärbung trat in allen Fällen ein, zeigte aber häufig einen Stich in's Braune.

Die erbaltenen Resultate sind in der nebenstehenden Tabelle zusammengestellt.

Von 30 untersuchten Thranen enthielten demnach 14 weniger als 1 Proc., 11 zwischen 1 und 2 Proc., 3 zwischen 2 und 3 Proc. und nur 2 Haifischthrane mehr als 3 Proc. unverseifbare Substanzen. Die Haifischthrane werden einerseits $z u$ den flüssigen Wachsen, andererseits zu den Leberthranen gerechnet. Die für die Nummern 27 bis 30 gefundenen Zahlen sprechen mehr für die letztere Annahme.

Bei den Dorschleberthranen enthalten die dunklen Sorten im Allgemeinen mebr Cholesterin als die hellen. Dies dürfte mit ihrer Gewinnung zusammenhängen, indem die Fischlebern beim kalten Pressen den hellen, beim nachfolgenden warmen Pressen den braunen Leberthran liefern. Des Weiteren dürfte aus den für die Leberthrane 
gefundenen Zahlen der Schluss zu ziehen sein, dass der von Jean angegebene Cholesteringehalt von 6 Proc. zwar ganz ausnahmsweise hoch, aber immerbin möglich ist.

\begin{tabular}{|c|c|c|c|}
\hline No & Bezelchnung des Thrans & Farbe & Unv \\
\hline 1 & Dampfmedicinalthran & hell & \\
\hline 2 & - & rblos & , \\
\hline 3 & - & bel & 0, \\
\hline 4 & Officineller Leberthran & rot & 0 \\
\hline 5 & - & & \\
\hline 6 & & he & 1, \\
\hline$\tau$ & Technischer, gelbblanker & & \\
\hline & $\begin{array}{l}\text { Dorschthran } \\
\text { Technischer, gelbblanker }\end{array}$ & gelb & 0 \\
\hline & Dorschthran & ge & \\
\hline 9 & Englisehes Codoil & ge & \\
\hline 10 & Braunblanker Dorschthran & br & \\
\hline l & - & bi & \\
\hline 2 & & & \\
\hline 13 & Schwed. Dreik & & , \\
\hline 4 & Fischthr an & & 0, \\
\hline 15 & & & \\
\hline 16 & Leva & roth & \\
\hline 17 & Japanfischthran & ge & 0,2 \\
\hline 18 & - & ro & \\
\hline 9 & $x^{-}-$ & & \\
\hline 0 & Sardinenth & ge & 0 \\
\hline & - & ro & 0 \\
\hline 2 & Walfischthran, norwegischer & gelbr & 0 \\
\hline 3 & - & gelbbraun, trub & 1, \\
\hline 4 & - & & 1 \\
\hline 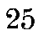 & Robbenthran, Astrachaner & ge & 0 \\
\hline & 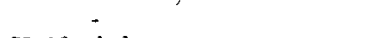 & ge & \\
\hline & Haifisebt & gelbroth & 0 \\
\hline & & & 18 \\
\hline & - & & \\
\hline & gendimpi & hellgelb & 5 \\
\hline
\end{tabular}

\section{Über die Ursache der Luftblasen im Tafelleim.}

Von

\section{Eugen Bergmann.}

Eine grosse Anzahl der im Handel vorkommenden Tafelleimsorten zeigt, gegen das Licht gehalten, zahlreiche eingeschlossene Luftblasen. Dieselben entstehen wäbrend des Trocknens der Gallerte, zeigen sich anfangs als kleine Pünktchen, nehmen bei fortschreitendem Trocknen an Grösse zu, erreichen im fertigen Producte bis Erbsengrösse und treten in den einzelnen Tafeln gewöhnlich massenhaft auf.

Die Erklärung dieser für den Fabrikanten unangenehmen Erscheinung hat meines Wissens noch keine befriedigende Lösung gefunden.

Da Leimgallerte ein guter Nährboden für Mikroorganismen ist, so lag die Annahme nahe, dass Kleinlebewesen, welche bei Luftabschluss existiren (Anaëroben) und dabei Gase als Stoffwechselproducte ausscheiden können, der Ursache der Blasenbildung nahe stehen dürften. Dies ist deshalb wahrscheinlich, weil sich die Luftblasen erst bilden, wenn die äusseren Partien der Tafeln durch's Trocknen hart, hornig und undurchlässig geworden sind.

Von mir angestellte Versuche durch sorgfältiges Sterilisiren der Gallerte durch Hitze, Carbolsäure, Salicylsäure und andere bakterientödtende Mittel zeigten, dass das Sterilisiren keinen Einfluss auf die Blasenbildung hat, denn solche Gallerte zeigte bei raschem Trocknen ebensoviel Luftblasen wie nicht sterilisirte.

Dass andere Ursachen als Kleinlebewesen zu Grunde liegen müssten, war auch schon deshalb anzunehmen, weil die Luftblasen im Winter gewöhnlich grösser werden und zahlreicher auftreten als im Sommer, während doch bekanntlich sich die Mikroorganismen in der heissen Jahreszeit in grösserer Anzahl in unserer Atmosphäre finden und die Aussentemperatur zu ihrer Entwickelung förderlicher ist.

Ferner beobachtet man, dass bei gleichmässig dicken Gallerte-Tafeln jene am meisten Luftblasen zeigen, welche am raschesten getrocknet wurden.

Ich finde die ungezwungenste Erklärung für das Auftreten der Luftblasen in den Tafeln in dem Vermögen des in der Gallerte enthaltenen Wassers, die atmosphärische Luft zu absorbiren. Die relativ grosse Oberfläche der Leimgallerte-Tafeln und die niedere Temperatur derselben im Winter begünstigen die Absorption.

Das raschere Übertrocknen der Tafeln im Winter, wenn die kalte Luft durch Erwärmen um 20 bis $30^{\circ}$ auf ein höheres Aufnahmevermögen für Wasserdampf gebracht werden kann, als im Sommer, bewirkt, dass die Oberfläche der Leimtafel hart und undurchlässig für Gase wird, wodurch die in dem Innern der Tafel befindliche, im Wasser der Gallerte absorbirte Luft nicht mehr entweichen kann. Bei fortschreitendem Trocknen wird die Luft ihres Lösungsmittels, des Wassers, beraubt, so dass sie sich in Form der bekannten Blasen im Leim ausscheiden muss.

Wie die Erfahrung zeigt, kann man auch die Luftblasen in den fertigen Leimtafeln vollständig vermeiden, wenn das Trocknen so geleitet wird, dass sich eine für Luft undurchlässige trockene Schicht im Anfangsstadium nicht bilde.

Chem. Fabrik "Ceres", Brzezie bei Ratibor, den 18. Febr. 1893. 